\title{
Factors Influencing Customers' Purchase Intention under C2B Model
}

\author{
Taiye Luo ${ }^{\mathrm{a}}$, Juanjuan $\mathrm{Qu}{ }^{\mathrm{b},{ }^{*}}$ \\ Xinhua College of Sun Yat-sen University,Guangzhou, China \\ aluoty06@163.com, ${ }^{\text {}}$ qjj689@163.com \\ ${ }^{*}$ Corresponding author
}

Keywords : customer integration capacity,co-creation, C2B,purchase intention.

\begin{abstract}
In this paper, we conducted an empirical study to explore factors which can affect customers' purchase intention under C2B model. Especially, we examined the role customer integration capacity (CIC) plays when customers purchase personalized products. We revealed that perceived value, perceived ease of use, perceived risk and CIC have significant impact on purchase intention. CIC is also found to be positively correlated with perceived value and perceived ease of use. Thus, CIC is an important indicator of customers' purchase intention under C2B model.
\end{abstract}

\section{Introduction}

With the rapid development of information technology, a new e-commerce model called C2B (customer to business) has been put forth in recent years. Differing from traditional e-commerce models, C2B model enables customers to get products tailored to their needs. Under C2B model, customers play an important role as they engage in product co-creation activities. They convey information and decisions on products (color, shape, size, etc.) directly to the providers. A concept named customer integration capacity (CIC) is proposed in this context to describe whether customers have sufficient knowledge and expertise to integrate themselves in this process. There exist some studies which analyzed customers' motivation to participate in co-creation (Benlian, 2015) and customers' perceived value as the result of engagement into co-creation (Grimal, 2014). However these studies focused on external factors (system quality, perceived value, seller characteristics, etc.) which may affect customers' participation intention or satisfaction. Customers' inner strength, such as CIC, so far has been ignored. It is worth knowing how CIC influences customers' purchase intention so as to better involve customers in the process. Therefore, in this paper we introduce CIC into the research model and try to answer the following questions: Are there any associations between CIC and the external factors which may have impact on customers' purchase intention? Can CIC influence purchase intention?

\section{Literature Review}

\subsection{Customer integration capability (CIC)}

CIC describes the skills a customer needs to collaborate in interactive value adding processes in order to co-design products smoothly, effectively and to their own satisfaction (Theilmann\&Hukauf, 2014). To date, several scholars have studied CIC. Müller (2007) proposed a scale to measure CIC and tested its relationships with other latent variables, e.g. customer satisfaction, service quality, etc. Based on Müller's work, Theilmann and Hukauf (2014) conducted an empirical study to test the multidimensional correlations of CIC with some constructs, such as customer satisfaction and customer perceived value, which companies treat as factors of business success. 


\subsection{Purchase intention under customization model}

Researchers have identified two sources of value in customization: the product value (utilitarian, individualism, self-expression) and the customization experience value (hedonism, pride). Some experiments (Franke et al., 2010; Fogliatto et al., 2012) validated the influence of these value drivers on customers' willingness to pay for MC products. Based on the stimulus-organism-response framework, Benlian (2015) developed a research model that proposes users' preference fit and perceived enjoyment as two key intervening mechanisms that carry over the differential effects of content and design personalization cues on users' willingness to pay for website offerings.

\section{Hypotheses}

\subsection{The effect of perceived value on purchase intention}

The value customers can derive from customization can be classified into customized product value and co-design experience value. The research conducted by Merle et al. (2010) revealed that both product value and experience value have direct positive impact on the overall value of customization, and the overall perceived value of customization has a positive influence on the intention of purchasing the customized product. Similarly, some other studies on the perceived value also view it as an antecedent to the purchase intention under customization model (Franke et al., 2010). The nature of $\mathrm{C} 2 \mathrm{~B}$ model is online customization. Thus, we propose:

H1a: Product value has positive impact on overall perceived value.

$\mathrm{H} 1 \mathrm{~b}$ : Experience value has positive impact on overall perceived value.

H2: Perceived value has positive impact on purchase intention.

\subsection{The effect of perceived ease of use on purchase intention}

Perceived ease of use refers to the degree to which a person believes that adopting the technology will be free of effort. Under C2B model, if the designer on the web page does not greatly increase the effort required to complete a product design, customers may consider it easy to use and will be more likely to adopt this new model. Therefore, we propose:

H3: Perceived ease of use has positive impact on purchase intention.

The perceived ease of use can be affected by some factors. Information quality, system quality and service quality are three dimensions which are considered to have impact on the success of information systems (DeLone and McLean, 2004). Under C2B model, if the information about how to involve in the co-design process is inaccurate or difficult to understand, consumers may think the process is complicated or not easy to manipulate. If the web pages are loaded or respond slowly, customers may think the process is effort-consuming. If the e-commerce website fails to provide customers with quality service that can assist them to achieve their specific goals, such as customizing a product, their perceived complexity may increase. Thus, we propose:

H4a: Information quality has impact on perceived ease of use.

H4b: Website quality has impact on perceived ease of use.

H4c: Service quality has impact on perceived ease of use.

\subsection{The effect of perceived risk on purchase intention}

Although C2B model can offer customers great value, it also gives rise to some problems, such as privacy protection, longer delivery time and no returns. Further, it may be difficult for some consumers to visualize customization outcomes. Moon and Lee (2014) pointed out that consumers may experience higher levels of risk in the online customization shopping context than in store or non-store settings because of their lack of confidence in the co-design process and uncertainty about its consequences. Thus, we propose:

H5: Perceived risk has negative impact on purchase intention. 


\subsection{The effect of CIC on purchasing intention}

Previous studies (Müller,2007; Theilmann and Hukauf, 2014) developed scales to measure CIC, in which CIC was measured by variables such as customers' knowledge and experience about co-creation, soft skills, methodological skills, etc. They also revealed CIC has positive impact on perceived value. Consumers' self-perception of their web skills can influence their perceived control of online customization and ease of use (Lee and Chang, 2011). Customers with more experience about online customization and better skills may be more confident in the co-creation process and perceive lower complexity or risk. Thus, we propose:

H6a: The higher the customers' CIC, the higher their perceived value.

H6b: The higher the customers' CIC, the higher their perceived ease of use.

H6c: The higher the customers' CIC, the lower their perceived risk.

The ability to express preferences will positively affect perceived preference fit with online customization (Moon and Lee, 2014). The more experience, the better soft skills and the stronger computer skills a customer has, he or she may be able to complete the co-creation process more smoothly, and the product may better fit their needs. Consequently, they are more willing to pay for the personalized product. Therefore, we propose:

H7: CIC has positive impact on purchase intention.

\section{Research design}

\subsection{Measurements}

Each of construct in the research model is measured with multiple items. Especially, a total number of 15 questions were used to measure CIC. The items were adapted from extant literature to fit C2B situation. All items were measured on a five-point Likert scale ranging from "strongly disagree"(1) to "strongly agree"(5).

\subsection{Data collection}

With the help of an online shop on Taobao.com, the largest e-commerce platform in China, we invited 319 customers who visited the shop to fill in a questionnaire. The shop sells customized T-shirts. Customers can upload images or input words which they want to print on the T-shirt. The images or words can appear on any position (left, right, front, back) of the T-shirt.

\subsection{Validity and reliability}

We conducted confirmatory factor analysis (CFA) to examine the scales' reliability and validity. Table 1 lists the standardized item loadings, CR, Cronbach's alpha and average variance extracted (AVE) of each construct, which suggest good convergent validity and reliability of the scale.

Table 1. Validity and Reliability

\begin{tabular}{|c|c|c|c|c|c|}
\hline Constructs & Items & loadings & $\mathrm{CR}$ & Cronbach's alpha & AVE \\
\hline \multirow{3}{*}{ CIC } & EXP & .688 & & \multirow{3}{*}{.722} & \multirow{3}{*}{.583} \\
\hline & SK & .775 & .80 & & \\
\hline & MK & .821 & & & \\
\hline \multirow{3}{*}{ information quality } & IQ1 & .863 & & \multirow{3}{*}{.888} & \multirow{3}{*}{.725} \\
\hline & IQ2 & .858 & .88 & & \\
\hline & IQ3 & .833 & & & \\
\hline \multirow{3}{*}{ website quality } & WQ1 & .763 & & \multirow{3}{*}{.783} & \multirow{3}{*}{.554} \\
\hline & WQ2 & .815 & .78 & & \\
\hline & WQ3 & .645 & & & \\
\hline \multirow{3}{*}{ service quality } & SQ1 & .677 & & \multirow{3}{*}{.709} & \multirow{3}{*}{.571} \\
\hline & SQ2 & .846 & .19 & & \\
\hline & SQ3 & .735 & & & \\
\hline \multirow{2}{*}{ perceived value } & PV1 & .739 & .78 & \multirow{2}{*}{.795} & \multirow{2}{*}{.551} \\
\hline & PV2 & .767 & 6 & & \\
\hline
\end{tabular}




\begin{tabular}{|c|c|c|c|c|c|}
\hline & PV3 & .721 & & & \\
\hline \multirow{3}{*}{ perceived ease of use } & PEOU1 & .753 & & \multirow{3}{*}{.858} & \multirow{3}{*}{.673} \\
\hline & PEOU2 & .874 & .86 & & \\
\hline & PEOU3 & .829 & & & \\
\hline \multirow{3}{*}{ perceived risk } & PR1 & .752 & & \multirow{3}{*}{.754} & \multirow{3}{*}{.512} \\
\hline & PR2 & .657 & .75 & & \\
\hline & PR3 & .734 & & & \\
\hline \multirow{3}{*}{ product value } & PRV1 & .681 & & \multirow{3}{*}{.776} & \multirow{3}{*}{.563} \\
\hline & PRV2 & .832 & .19 & & \\
\hline & PRV3 & .729 & & & \\
\hline \multirow{3}{*}{ experience value } & EV1 & .772 & & \multirow{3}{*}{.808} & \multirow{3}{*}{.590} \\
\hline & EV2 & .692 & .81 & & \\
\hline & EV3 & .834 & & & \\
\hline \multirow{3}{*}{ purchase intention } & PI1 & .830 & & \multirow{3}{*}{.834} & \multirow{3}{*}{.637} \\
\hline & PI2 & .856 & $\begin{array}{c}.83 \\
0\end{array}$ & & \\
\hline & PI3 & .700 & & & \\
\hline
\end{tabular}

note: EXP: expertise; SK: soft skills; MK:Methodological skills.

Further calculation reveals that, for each construct, the square root of AVE is larger than its correlation coefficients with other constructs. Thus, the scales have good discriminant validity.

\subsection{Model test}

AMOS 21.0 was employed to test the structural model and hypotheses. A similar set of fit indices was used to examine the structural model. As Table 2 shows, comparison of all fit indices with their corresponding recommended values suggests a good model fit.

Table 2. Values of Fit Indices

\begin{tabular}{ccccccc}
\hline Fit index & $\chi 2 / \mathrm{df}$ & CFI & NFI & IFI & GFI & MSEA \\
\hline Recommended value & $<3$ & $>0.9$ & $>0.9$ & $>0.9$ & $>0.9$ & $<0.08$ \\
Actual value & 1.88 & 0.93 & 0.94 & 0.95 & 0.91 & 0.07 \\
\hline
\end{tabular}

Figure1 presents the results of path analysis.

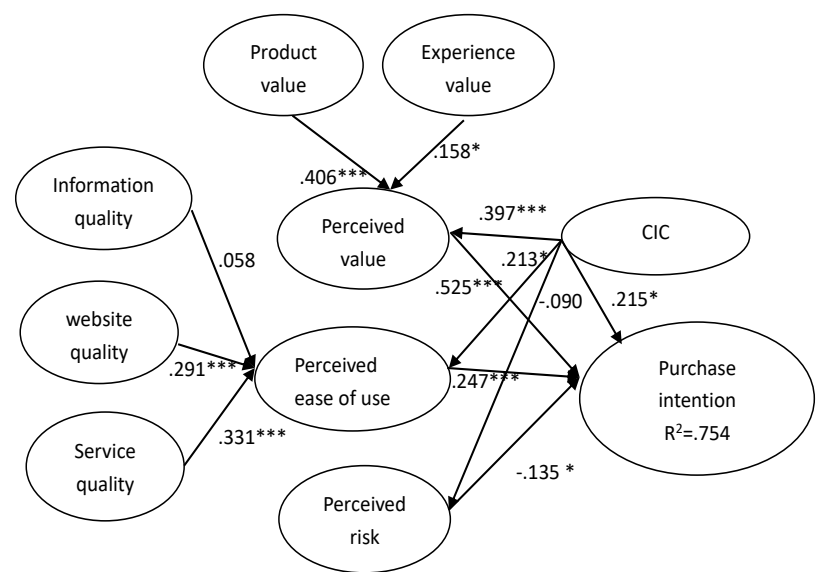

Figure 1 Path analysis results

As Figure 2 shows, product value $(\beta=0.406, p<0.001)$ and experience value $(\beta=0.158, p<0.05)$ have positive impact on overall perceived value, supporting $\mathrm{H} 1 \mathrm{a}$ and $\mathrm{H} 1 \mathrm{~b}$. Both perceived value $(\beta=0.525, \mathrm{p}<0.001)$ and perceived ease of use $(\beta=0.247, \mathrm{p}<0.001)$ can significantly influence purchase intention, confirming H2 and H3. Website quality $(\beta=0.291, \mathrm{p}<0.001)$ and service quality $(\beta=0.331, p<0.001)$ can positively affect perceived ease of use. Thus, H4b and H4c are supported. Information quality $(\beta=0.058, p=0.111)$ has no significant impact on perceived ease of use, rejecting H4a. Perceived risk $(\beta=-0.135, p<0.05)$ has negative effect on purchase intention, supporting H5. CIC is positively correlated with both perceived value $(\beta=0.397, p<0.001)$ and perceived ease of use 
$(\beta=0.213, p<0.05)$, but not negatively correlated with perceived risk $(\beta=-0.090, p=0.103)$, confirming H6a and H6b, rejecting H6c. CIC $(\beta=0.215, \mathrm{p}<0.05)$ also has positive impact on purchase intention. Therefore, $\mathrm{H} 7$ is supported.

\section{Conclusion}

The major objective of this research is to examine the role CIC plays in customers' purchase decision-making. This study contributes to the customization literature by revealing that CIC can positively influence purchase intention under $\mathrm{C} 2 \mathrm{~B}$ model. Perceived value and perceived ease of use are two factors extensively used to explain why customers adopt an innovation. In this research, we found these two factors are not only relevant with external stimuli, but also associated with customers' inner characteristics under C2B model. Specifically, the higher CIC is, the higher perceive value and perceived ease of use will be.

One of the limitations of this study lies in the sample. We have considered a sample of customers focusing on only one type of customized product--T-shirt, which limits the generalizability of the findings to the broader customization market. Future research should consider a diverse range of customized products to provide a better understanding of the role of $\mathrm{CIC}$ under $\mathrm{C} 2 \mathrm{~B}$ model.

\section{Acknowledgement}

This research was supported by the Key Platforms and Major Scientific Research Projects for Universities in Guangdong Province (Grant NO 2016WQNCX187).

\section{References}

[1] Alexander Benlian. (2015).Web Personalization Cues and Their Differential Effects on User Assessments of Website Value.Journal of Management Information Systems, 32(1), 225-260.

[2] Claudia Theilmann, Martin Hukauf. (2014).Customer integration in mass customization: a key to corporate success. International Journal of Innovation Management, 18, 1440002-1-1440002-23.

[3] Franke, N., Schreier, M., Kaiser, U.(2010). The “I designed it myself”' effect in mass customization. Management Science 56 (1), 125-140.

[4] Fogliatto et al. (2012).The mass customization decade: An update d review of the literature. Int. J. Production Economics, 138, 14-25.

[5] Laurent Grimal, Philippe Guerlain. (2014). Mass customization in apparel industry - implication of consumer as co-creator. Journal of economics \& management,vol 15, 106-121.

[6] Lee, H.H. and Chang, E. (2011). Consumer attitudes toward online mass customization. Journal of Computer-Mediated Communication, Vol. 16 No. 2, pp. 171-200.

[7] Aurelie Merle et al.(2010). Perceived Value of the Mass-Customized Product and Mass Customization Experience for Individual Consumers. Production and Operations Management Society, Vol. 19, No. 5, 503-514.

[8] Müller, M (2007). Integrationskompetenz von Kunden bei individuellen Leistungen: Konzeptualisierung, Operationalisierung und Erfolgswirkung. Wiesbaden: Deutscher Universitätsverlag.

[9] Moon, H., \& Lee, H.-H. (2014). Consumers' preference fit and ability to express preferences in the use of online mass customization. Journal of Research in Interactive Marketing, 8, 124-143.

[10] W.H. DeLone, E.R. McLean. Measuring e-commerce success: applying the DeLone and McLean information systems success model, Int. J. Electron. Commer. 9 (1), 2004, pp. 31-47. 